\title{
21. OXYGEN AND HYDROGEN ISOTOPE STUDIES IN SQUEEZED PORE WATERS, DEEP SEA DRILLING PROJECT LEG 74, HOLE 525B: EVIDENCE FOR MID-MIOCENE OCEAN ISOTOPIC CHANGE ${ }^{1}$
}

\author{
Adrian Bath, Hydrogeology Unit, Institute of Geological Sciences, Wallingford, OX10 8BB, England \\ and \\ Nicholas Shackleton, The Godwin Laboratory, Free School Lane, Cambridge, CB2 3RS, England
}

\begin{abstract}
During the coring of Hole 525B with the hydraulic piston corer, a number of sediment samples were squeezed and the pore waters retained for stable isotope study. Both ${ }^{18} \mathrm{O} /{ }^{16} \mathrm{O}$ and $\mathrm{D} / \mathrm{H}$ ratios were determined on the same samples. Within the limits of experimental error the measurements are consistent with the variations resulting from evaporationprecipitation processes; there is no evidence that diagenetic processes in the sediment affected the isotopic composition of the waters, which therefore reflect changes in the isotopic composition of the ocean during the Cenozoic. The data are consistent with the hypothesis that a change of about $0.9 \%\left({ }^{18} \mathrm{O} /{ }^{16} \mathrm{O}\right)$ occurred during the middle Miocene, reflecting the growth of the Antarctic ice sheet at that time.
\end{abstract}

\section{INTRODUCTION}

Emiliani (1955) was the first to estimate the likely change in the isotopic composition of the ocean which would result from the disappearance of the Antarctic ice sheet. His estimate was based largely on the isotopic composition of icebergs, the only source of information available at that time. Craig (1965) made a new estimate with the benefit of more experimental data. Shackleton (1967) and Shackleton and Kennett (1975) considered the steady-state isotopic composition of the ice sheet in three dimensions; these workers showed that the bulk isotopic composition is critically affected by the isotopic composition of the snow falling in the central region, and had the benefit of new isotopic data from inland Antarctica. We now know that even these compilations slightly underestimate the bulk isotopic composition, since we know from borehole work that even in central Antarctica snow which fell during the last glacial was slightly lighter isotopically than the snow that is falling now (Lorius et al., 1979); much of the ice stored now was formed during the last glacial. Taking all these factors into account, it would appear that if the presently existing ice on Antarctica and on Greenland were melted and mixed back into the oceans, the average isotopic composition of the oceans would be at least $0.9 \%$ lighter for ${ }^{18} \mathrm{O}$, or $7 \%$ lighter for $\mathrm{D} / \mathrm{H}$.

Shackleton and Kennett (1975) argued that the oxygen isotope record they obtained for benthic foraminifers showed the effect of Antarctic ice buildup in the middle Miocene. Although this conclusion has been widely accepted, it has recently been challenged by Matthews and Poore (1981). For this reason, it seemed appropriate to seek direct evidence for the event.

Friedman and Hardcastle (1973) and Friedman (pers. comm. to N.J.S., 1980 and 1981) have made D/H mea-

\footnotetext{
${ }^{1}$ Moore, T. C., Jr., Rabinowitz, P. D., et al., Init. Repts. DSDP, 74: Washington (U.S. Govt. Printing Office).
}

surements in pore waters from the upper parts of a number of DSDP sites and find that they are consistent with an isotopic change during the middle Miocene. Friedman's work is an important direct check on the ocean isotopic change during the Miocene. However, his data are scattered over many sites from various oceans and depths; additionally, they represent sediments recovered by rotary coring, with attendant risk of contamination by recent seawater. For this reason we planned a dense sampling. at a single HPC site, in carbonate-rich sediments in which the region of interest was well separated from underlying basalt and hence reasonably protected from those minerals that most readily exchange isotopically. Site 525 best suited these requirements.

\section{METHODS}

On board ship, samples were squeezed and sealed in glass ampoules in the manner standard for interstitial water studies (Gieskes, 1974).

Analyses of ${ }^{18} \mathrm{O} /{ }^{16} \mathrm{O}$ and $\mathrm{D} / \mathrm{H}$ ratios on $\mathrm{CO}_{2}$ and $\mathrm{H}_{2}$ gases, respectively, were carried out on a VG Isogas double collection mass spectrometer at Wallingford. Carbon dioxide was prepared by equilibration with $4 \mathrm{ml}$ water samples at constant temperature, according to the method first described by Epstein and Mayeda (1953). The isotopic composition of the water was estimated from the value measured for the carbon dioxide using the relationships given by Craig (1957). Hydrogen gas for analysis was prepared by passing a $10 \mu \mathrm{l}$ sample of water over heated uranium metal at $800^{\circ} \mathrm{C}$ and collecting the resulting hydrogen by the reversible formation of uranium hydride. Samples of a calibrated working standard water were simultaneously analyzed, permitting the calibration of results with respect to the conventional Vienna-SMOW standard and the estimation of appropriate standard deviations. Results are given using the $\delta$ notation, that is, $\delta=$ $\left(R_{\text {sample }} /\left(R_{\text {standard }}-1\right) \times 1000, R\right.$ being the ${ }^{18} \mathrm{O} /{ }^{16} \mathrm{O}$ ratio for $\delta^{18} \mathrm{O}$ and $\mathrm{D} / \mathrm{H}$ for $\delta \mathrm{D}$; the unit is \%. The estimated standard deviations are better than $\pm 0.1 \%$ for $\delta^{18} \mathrm{O}$ and $\pm 1 \%$ for $\delta \mathrm{D}$.

\section{RESULTS}

Analytical data are shown in Table 1. Figure 1 shows a plot of $\delta^{18} \mathrm{O}$ versus $\delta \mathrm{D}$ for all samples, together with estimated analytical errors. It will be seen that with two exceptions, all points are consistent with a line representing the abstraction from ocean water of atmospheric 
Table $1 .{ }^{18} \mathrm{O} /{ }^{16} \mathrm{O}$ and $\mathrm{D} / \mathrm{H}$ values for pore waters from DSDP Hole 525B, with respect to the Vienna-SMOW standard.

\begin{tabular}{|c|c|c|c|c|c|c|}
\hline $\begin{array}{l}\text { Core-Section } \\
\text { (interval in } \mathrm{cm} \text { ) }\end{array}$ & $\begin{array}{l}\text { Depth } \\
\text { below } \\
\text { seafloor } \\
\text { (m) }\end{array}$ & ${ }^{18} \mathrm{O}$ & \multicolumn{2}{|c|}{$\delta \mathrm{D}$} & $\begin{array}{c}\text { Mean } \\
\text { scaled } \\
\text { for } \delta^{18} \mathrm{O}\end{array}$ & $\begin{array}{l}\text { 3-point running } \\
\text { mean }\end{array}$ \\
\hline $1-1,140-150$ & 1.45 & -0.13 & -2.7 & -1.3 & $-0.21 \pm 0.11$ & \\
\hline $3-1,140-150$ & 9.35 & 0.00 & -0.1 & -0.5 & $-0.03 \pm 0.03$ & $-0.08 \pm 0.13$ \\
\hline $5-2,133-143$ & 19.58 & +0.15 & -0.7 & -0.3 & $+0.06 \pm 0.13$ & $+0.02 \pm 0.08$ \\
\hline $7-2,140-150$ & 28.45 & +0.11 & +0.2 & +0.7 & $+0.08 \pm 0.04$ & $+0.01 \pm 0.09$ \\
\hline $9-3,111-121$ & 38.46 & 0.00 & -0.9 & -0.4 & $-0.05 \pm 0.06$ & $+0.02 \pm 0.10$ \\
\hline $11-2,140-150$ & 46.05 & -0.12 & +1.5 & +0.2 & $+0.03 \pm 0.16$ & $-0.02 \pm 0.13$ \\
\hline $13-2,140-150$ & 54.85 & +0.17 & -0.9 & -1.6 & $-0.05 \pm 0.19$ & $-0.02 \pm 0.13$ \\
\hline $15-1,140-150$ & 62.15 & -0.01 & -0.5 & -0.9 & $-0.06 \pm 0.05$ & $-0.08 \pm 0.13$ \\
\hline $17-1,140-150$ & 70.95 & 0.00 & -2.3 & -1.1 & $-0.14 \pm 0.15$ & $-0.07 \pm 0.11$ \\
\hline $19-2,140-150$ & 81.25 & +0.02 & +0.5 & -0.9 & $-0.01 \pm 0.09$ & $-0.08 \pm 0.11$ \\
\hline $22-2,140-150$ & 94.45 & -0.02 & -0.6 & -1.5 & $-0.10 \pm 0.09$ & $-0.06 \pm 0.08$ \\
\hline $24-2,140-150$ & 102.25 & -0.11 & -0.2 & -0.6 & $-0.07 \pm 0.04$ & $-0.16 \pm 0.15$ \\
\hline $26-2,140-150$ & 111.05 & -0.51 & -2.0 & -1.7 & $-0.32 \pm 0.16$ & $-0.12 \pm 0.21$ \\
\hline $29-2,140-150$ & 124.25 & Lost & +0.6 & +1.4 & $+0.13 \pm 0.07$ & $-0.13 \pm 0.22$ \\
\hline $31-2,140-150$ & 133.15 & -0.06 & -0.5 & -1.8 & $-0.12 \pm 0.10$ & $-0.16 \pm 0.23$ \\
\hline $33-2,140-150$ & 141.95 & -0.38 & -3.4 & -3.3 & $-0.41 \pm 0.03$ & $-0.24 \pm 0.26$ \\
\hline $35-1,140-150$ & 149.25 & -0.69 & -0.4 & +1.1 & $-0.20 \pm 0.43$ & $-0.25 \pm 0.26$ \\
\hline $37-2,140-150$ & 159.55 & 0.00 & -2.1 & -1.3 & $-0.14 \pm 0.13$ & $-0.22 \pm 0.27$ \\
\hline $39-2,140-150$ & 168.35 & -0.04 & -3.6 & -4.2 & $-0.33 \pm 0.26$ & $-0.25 \pm 0.17$ \\
\hline $42-1,140-150$ & 175.65 & -0.37 & -1.5 & -2.5 & $-0.29 \pm 0.09$ & $-0.32 \pm 0.18$ \\
\hline $45-3,140-150$ & 191.85 & -0.45 & -4.6 & -4.1 & $-0.51 \pm 0.07$ & $-0.39 \pm 0.13$ \\
\hline $47-3,140-150$ & 200.65 & -0.40 & -1.7 & -3.6 & $-0.35 \pm 0.13$ & $-0.38 \pm 0.15$ \\
\hline $49-3,140-150$ & 209.45 & -0.42 & -1.3 & -1.9 & $-0.27 \pm 0.13$ & $-0.44 \pm 0.21$ \\
\hline $51-1,135-150$ & 273.72 & -0.71 & -5.6 & -5.2 & $-0.69 \pm 0.03$ & $-0.48 \pm 0.24(2 \mathrm{pt})$. \\
\hline
\end{tabular}

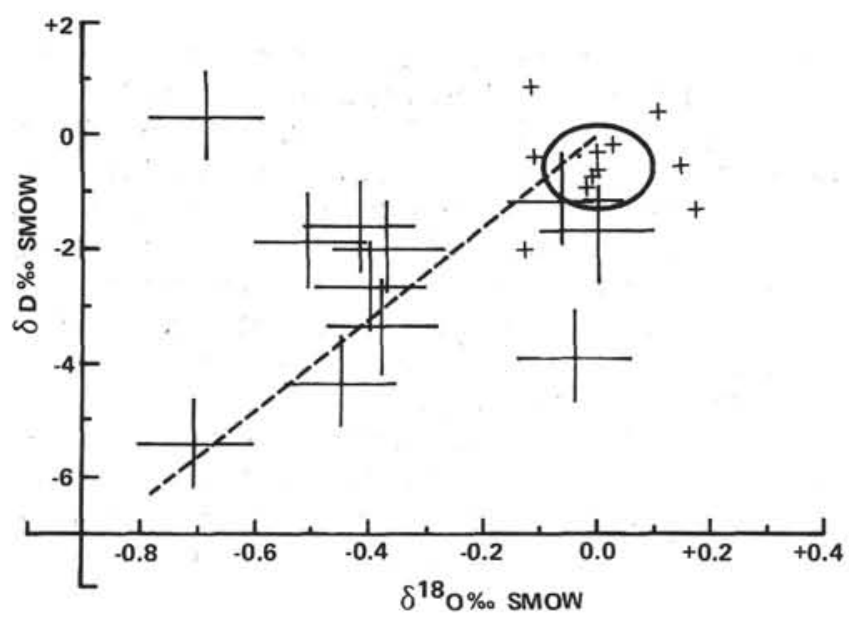

Figure 1. Plot of $\delta \mathrm{D}$ versus $\delta^{18} \mathrm{O}$ for Hole $525 \mathrm{~B}$ pore waters, from Table 1. Because the data points for the top 12 samples are close to the origin, an ellipse is drawn to represent the mean and standard deviation of all these analyses. For the remaining samples, error bars are drawn on the assumption that variability among the top 12 samples is a reliable estimate of total analytical uncertainties. The dashed line reflects the predicted effect of removing ice of the composition of Antarctic ice from ocean water, that is, a slope of 8 .

precipitation at typical Antarctic values with a $\delta \mathrm{D} / \delta^{18} \mathrm{O}$ ratio of 8.0 (Craig and Gordon, 1965). In Table 1 we have pooled all the analytical data by converting $\mathrm{D} / \mathrm{H}$ values to equivalent ${ }^{18} \mathrm{O}$ values (dividing by 8 ) and show the mean and standard deviation for each level. The results are plotted against depth in hole in Figure 2.

It is unlikely that the scatter observed in Figure 2 is real; one would expect that diffusion would smooth out any short-wavelength fluctuations even if they were originally present. Although we are puzzled by the apparent consistency of the individual determinations, we consider that it is appropriate to treat the observed fluctuations as random noise, and to smooth the data by taking a three-point running mean (which generally averages nine independent measurements). Figure 3 compares the oxy-

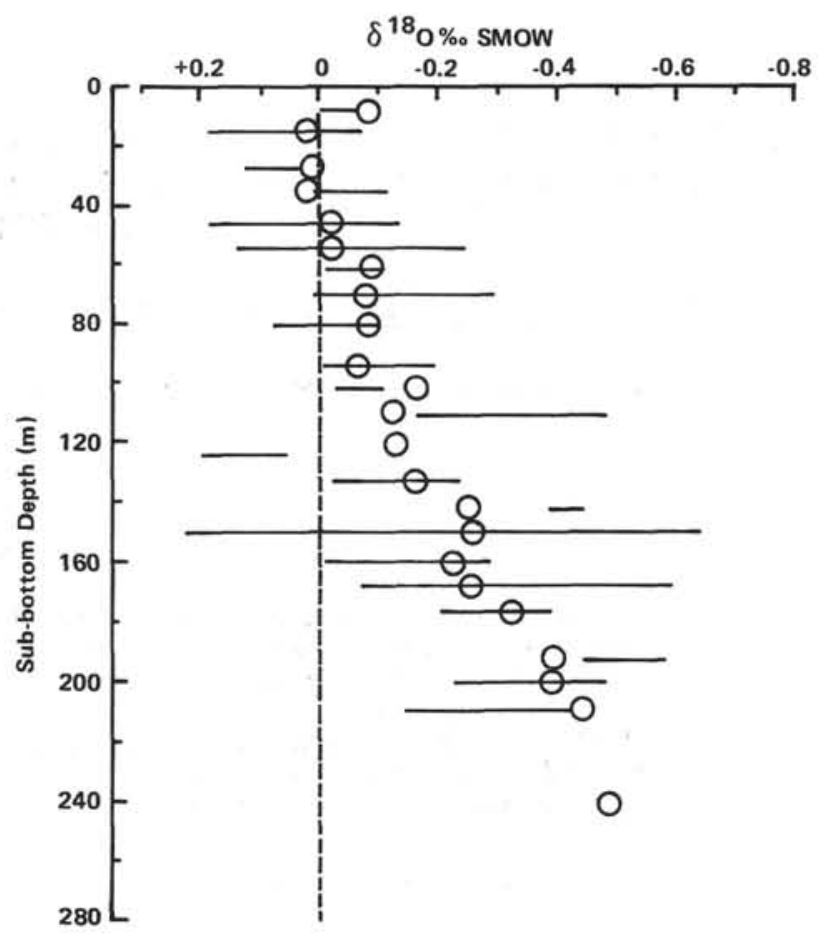

Figure 2. Plot of pooled isotopic analyses (scaled for $\delta^{18} \mathrm{O}$ ) versus depth below seafloor in Hole 525B. Here lines represent apparent standard deviations among the three analyses (two $\mathrm{D} / \mathrm{H}$, one ${ }^{18} \mathrm{O}$ ) on each sample. Circles indicate three-point running mean values.

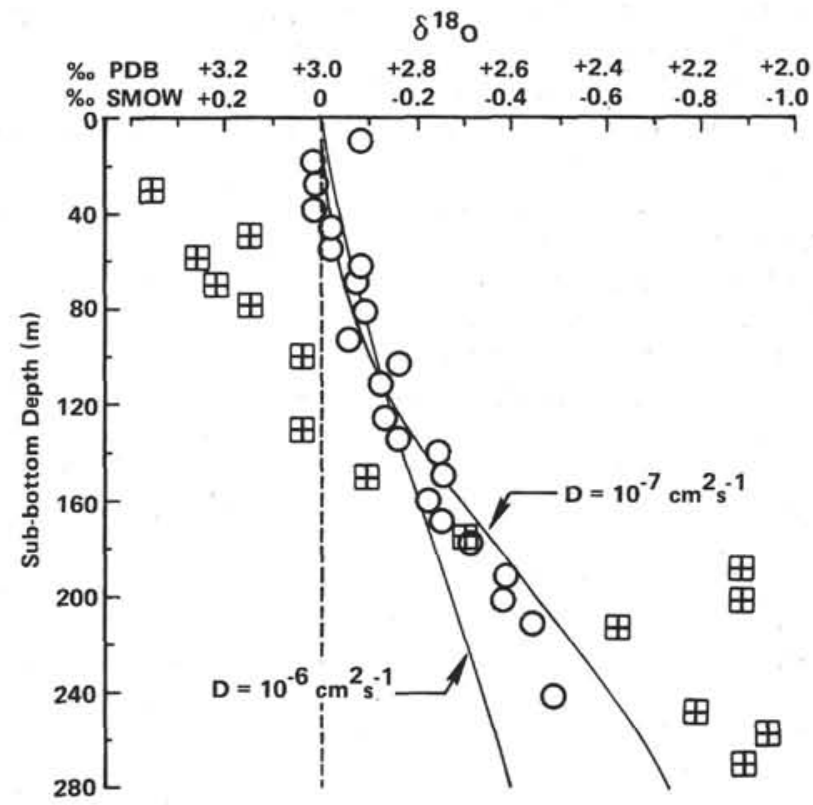

Figure 3. Three-point running mean pore water data from Figure 2 (circles, to SMOW, lower scale); oxygen isotope data from benthic foraminifers, from Shackleton, Hall, and Boersma (this volume) (squares, to PDB, upper scale), and pore water gradients predicted for two different values of the diffusion constant $D$, assuming that the ocean isotopic composition was $-0.9 \%$ before $14 \mathrm{Ma}$.

gen isotope record of benthic foraminifers from the same site (from Shackleton, Hall, and Boersma, this volume) and the smoothed pore water data. It will be seen that both show a similar shift, although the change appears 
more rapid in the foraminiferal record than in the pore water record. This is to be expected, as a result of selfdiffusion in the water. Dotted lines indicate the extent to which a steplike change in ocean isotopic composition to present-day values $14 \mathrm{Ma}$ would be expected to have been modified by diffusion, using two values for the self-diffusion constant of water in sediment. The calculations are based on a rapid change in isotopic composition at $14 \mathrm{Ma}$, and a uniform accretion of sediment since that time, using the relationship

$$
\frac{c(z, t)}{c_{0}}=1-\frac{1}{2} \operatorname{erfc} \frac{z-z_{0}}{(4 \mathrm{D} t)^{1 / 2}}+\exp \frac{z z_{0}}{\varrho t} \operatorname{erfc} \frac{z+z_{0}}{(4 \mathrm{D} t)^{1 / 2}},
$$

in which

$$
\begin{aligned}
z_{0} & =180 \mathrm{~m} \\
c_{0} & =-0.9 \% \text { when } t=0 \text { and } z>0 \\
\mathrm{c} & =0.0 \% \text { when } t>0 \text { and } z=0
\end{aligned}
$$

At the measured porosities in Hole $525 \mathrm{~B}$, which average about $55 \%$, and using the relationship obtained by Manheim (1970) between apparent $D$ in sediment and the measured self-diffusion constant $D_{0}$, one would expect a value of $\mathrm{D}$ between $10^{-5}$ and $10^{-6} \mathrm{~cm}^{2} \mathrm{~s}^{-1}$. Our measurements suggest that a considerably lower value might be appropriate. The curve for a value of $10^{-7} \mathrm{~cm}^{2}$ $\mathrm{s}^{-1}$ appears to fit the data quite well. Rather more data, particularly from deeper in the section, would be needed to estimate the true diffusion constant accurately. However, it certainly appears that paleo-seawater is preserved in the sediments, and that the measurement of its isotopic composition confirms other evidence for the growth of the isotopically light Antarctic ice sheet during the mid-Miocene. The low effective diffusion constant implied by these data deserves further investigation. It is possible that the time and/or length scale on which the experimental determinations of the diffusion constant are based do not accurately describe diffusion in the sediment, or that the way in which water is distributed in the sediment is not adequately described, for diffusion purposes, but the simple factor "porosity." Although other workers have explained a downhole trend toward isotopically lighter pore-water ${ }^{18} \mathrm{O}$ values in terms of diagenesis (Baker et al., 1981), the relationship that we observe between ${ }^{18} \mathrm{O} /{ }^{16} \mathrm{O}$ and $\mathrm{D} / \mathrm{H}$ is unlikely to arise from diagenesis. The relationship between isotopic composition and depth that we have found might be better modelled with the higher diffusion constants postulated by these workers if we were to assume a lighter value for the isotopic composition of pre-Miocene seawater, and if we were to take into account the effect of changes in the isotopic composition of seawater during the past $2 \mathrm{~m}$.y. It will be necessary to sample a profile in even greater detail in order to resolve these problems.

\section{CONCLUSIONS}

1) In the sediments of Hole 525B (about $97 \%$ $\mathrm{CaCO}_{3}$ ) the ${ }^{18} \mathrm{O} /{ }^{16} \mathrm{O}$ and $\mathrm{D} / \mathrm{H}$ ratios in pore waters are consistent with the hypothesis that they reflect the history of ocean isotopic composition, modified by diffusion, although this conclusion requires a lower effective diffusion constant than is generally accepted.

2) The measurements support the hypothesis outlined by Shackleton and Kennett in 1975, that the oceans underwent an isotopic change during the middle Miocene as a result of the accumulation of a major ice sheet on Antarctica.

3) Further light could be thrown on this event and on diffusion in pore waters by a more extensive sampling program, in a similar site and also in a site with a higher accumulation rate.

\section{ACKNOWLEDGMENTS}

We thank the scientists and crew of the Glomar Challenger for making this study possible, and in particular Ken Thompson for carefully taking the samples for analysis. N.J.S. acknowledges N.E.R.C. grant GR3/3606. This paper is published with permission of the Director, Institute of Geological Sciences (N.E.R.C.). We are grateful to Joris Gieskes and Irving Friedman for reviewing the manuscript.

\section{REFERENCES}

Baker, P. A., Gieskes, J. M., and Elderfield, H., 1981. Diagenesis of carbonates in deep sea sediments-evidence from $\mathrm{Sr} / \mathrm{Ca}$ ratios and interstitial dissolved $\mathrm{Sr}^{++}$data. J. Sed. Petrol., 52:71-82.

Craig, H., 1957. Isotopic standards for carbon and oxygen and correction factors for mass spectrometric analysis of carbon dioxide. Geochim. Cosmochim. Acta, 12:133-149.

1965. The measurements of oxygen isotope palaeotemperatures. In Tongiorgi, E. (Ed.), Stable Isotopes in Oceanographic Studies and Palaeotemperatures: Pisa (Consiglio Nazionale delle Ricerche), pp. 3-24.

Craig, H., and Gordon, L. I., 1965. Deuterium and oxygen-18 variations in the ocean and the marine atmosphere. In Tongiorgi, E. (Ed.), Stable Isotopes in Oceanographic Studies and Palaeotemperatures: Pisa (Consiglio Nazionale delle Ricerche), pp. 9-130.

Emiliani, C., 1955. Pleistocene temperatures. J. Geol., 63:538-578.

Epstein, S., and Mayeda, T. K., 1953. Variations in the ${ }^{18} \mathrm{O} /{ }^{16} \mathrm{O}$ ratio in natural waters. Geochim. Cosmochim. Acta, 4:213-224.

Friedman, I., and Hardcastle, K., 1973. Interstitial water studies, Leg 15-isotopic composition of waters. In Heezen, B. C., MacGregor, I. D., et al., Init. Repts. DSDP, 20: Washington (U.S. Govt. Printing Office), 901-903.

Gieskes, J. M., 1974. Interstitial water studies, Leg 25. In Simpson, E. S. W., Schlich, R., et al., Init. Repts. DSDP, 25: Washington (U.S. Govt. Printing Office), 361-394.

Lorius, C., Merlivat, L., Jouzel, J., and Pourchet, M., 1979. A 30,000yr isotope climatic record from Antarctic ice. Nature, 280:644-648.

Manheim, F. T., 1970. The diffusion of ions in unconsolidated sediments. Earth Planet. Sci. Lett., 9:307-309.

Matthews, R. K., and Poore, R. Z., 1980. Tertiary $\delta^{18} \mathrm{O}$ record and glacio-eustatic sea-level fluctuations. Geology, 8:501-504.

Shackleton, N. J., 1967. The Measurement of Palaeotemperatures in the Quaternary Era [Ph.D. dissert.]. University of Cambridge.

Shackleton, N. J., and Kennett, J. P., 1975. Paleotemperature history of the Cenozoic and the initiation of Antarctic glaciation: Oxygen and carbon isotope analyses in DSDP Sites 277, 279 and 281. In Kennett, J. P., Houtz, R. E., et al., Init. Repts. DSDP, 29: Washington (U.S. Govt. Printing Office), 801-808. 